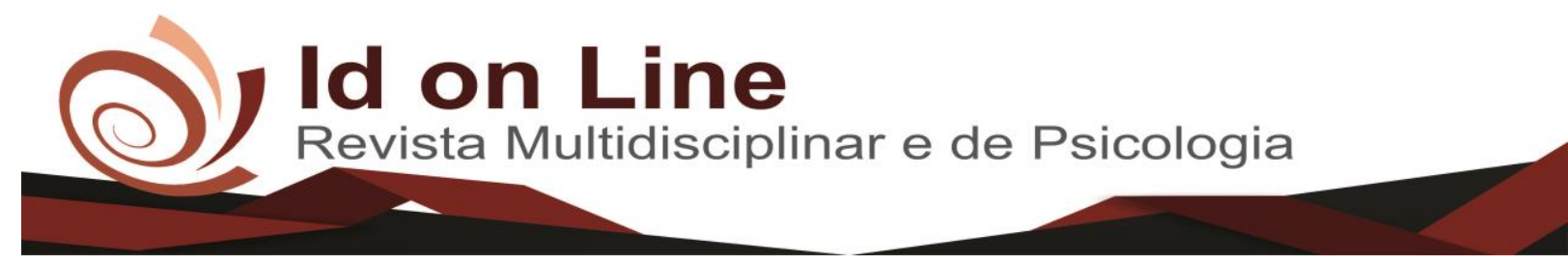

Artigo

\title{
A Percepção dos Trabalhadores Formais sobre a Gestão de Pessoas em Empresas Familiares
}

\author{
Inguily Maiane de Sousa Tavares ${ }^{1}$; Larissa Vasconcelos Rodrigues ${ }^{2}$
}

\begin{abstract}
Resumo: No mundo corporativo contemporâneo, a gestão de pessoas tornou-se essencial no processo decisório bem como uma ferramenta de vital importância para as estratégias de empresas que buscam adquirir uma vantagem competitiva. É notório que a grande maioria das empresas existentes no país hoje são organizações familiares, como é o que mostra a pesquisa de Empresas Familiares no Brasil (2016), cerca de 80\% das 19 milhões existentes. No Brasil, um estudo divulgado pela Fundação Dom Cabral - FDC em 2015 mostra que 60\% dos empregos formais existentes são ofertados por empresas familiares. Entretanto, uma organização familiar só mantem-se próspera por muitos anos se possuírem um bom modelo de gestão administrativa e, sobretudo uma boa gestão de pessoas. Os meios utilizados para obtenção das informações que se utilizou para investigação seguiram os princípios metodológicos convencionais. O instrumento mais adequado para a pesquisa em questão é a utilização de um breve questionário com perguntas objetivas e/ou subjetivas que de acordo com Marconi e Lakatos (2008), procuram sempre esclarecer o objetivo da natureza e da importância da pesquisa. Através da pesquisa conclui-se que na percepção dos trabalhadores formais do atual mercado, a gestão de pessoas profissional é de fundamental importância para as organizações, sobretudo dos familiares, principalmente quando se pretende obter vantagens competitivas sobre seus concorrentes bem como quando se tratar de planejamento estratégico a fim de melhorar e inovar as técnicas administrativas da organização.
\end{abstract}

Palavras-Chave: Empresa familiar, gestão de pessoas, vantagens competitivas

\section{Perception of Formal Workers on People Management in Family Companies}

\begin{abstract}
In the contemporary corporate world, people management has become essential in the decision-making process as well as a vitally important tool for the strategies of companies seeking to gain a competitive edge. It is notorious that the vast majority of companies in the country today are family organizations, as shown by the survey of Family Companies in Brazil (2016), about $80 \%$ of the 19 million that exist. In Brazil, a study released by Fundação Dom Cabral - FDC in 2015 shows that $60 \%$ of existing formal jobs are offered by family companies. However, a family organization only remains prosperous for many years if they have a good model of administrative management and above all a good management of people. The means used to obtain the information used for research followed conventional methodological principles. The most appropriate instrument for the research in question is the use of a brief questionnaire with objective and / or subjective questions that according to Marconi and Lakatos (2008) always seek to clarify the purpose of the nature and importance of the research. Through the research it is concluded that in the perception of the formal workers of the current market, the management of professional people is of fundamental importance for organizations, especially of the family, especially when it is intended to obtain competitive advantages over its competitors as well as when it comes to planning to improve and innovate the administrative techniques of the organization.
\end{abstract}

Keywords: Family business, people management, competitive advantages

\footnotetext{
${ }^{1}$ Graduanda do curso de Administração do Centro Universitário Doutor Leão Sampaio. Juazeiro do Norte, Ceará - Brasil. Contato: inguilymay@hotmail.com;

${ }^{2}$ Especialista e docente do curso de Administração e Psicologia do Centro Universitário Doutor Leão Sampaio. Juazeiro do Norte, Ceará - Brasil. Contato: larissavasconcelospsi@gmail.com.
} 


\section{Introdução}

No mundo corporativo contemporâneo, a gestão de pessoas tornou-se essencial no processo decisório bem como uma ferramenta de vital importância para as estratégias de empresas que buscam adquirir uma vantagem competitiva. Se bem trabalhada, a gestão de pessoas traz inúmeros benefícios para as empresas através de métodos que podem possibilitar o alcance mais rápido e eficiente dos objetivos da organização, economizando recursos essenciais como o tempo, por exemplo, bem como também pode se tornar um tipo de cultura organizacional para o mundo dos negócios. De acordo com Paula e Nogueira (2016), a gestão de pessoas representa o inicio do processo de gestão, pois é nela onde se avalia, seleciona e qualifica o colaborador para desenvolver atividades com maior qualidade e produtividade.

Mas isso é uma tarefa simples e requer do gestor muita experiência, pois administrar pessoas nunca foi um trabalho fácil, considerando todas as dificuldades já conhecidas desse tipo de recurso. Entretanto, não se pode esquecer que, as pessoas são os principais recursos disponíveis que uma empresa pode contar para obter sucesso e grandes resultados.

De acordo com a revista Exame (2015), no Brasil, as empresas de pequeno e médio porte, em sua maioria, são organizações familiares. A revista diz que ao longo dos anos e com o crescimento do negócio, acaba criando-se uma verdadeira confusão entre as relações profissionais e familiares, dando origem assim aos conflitos, que, quase sempre, terminam com a falência da empresa.

Segundo a revista, existe uma diferença entre "empresa familiar" e "família empresária". A revista afirma que no primeiro caso, é comum que as pessoas vinculadas no ambiente organizacional confundam laços de parentesco familiar, empresa e patrimônio e que por sua vez, acaba gerando decisões passionais levadas pelo sentimento de emoção. Enquanto que famílias empresárias possuem em seu núcleo os mesmos membros de uma empresa familiar, porém as tomadas de decisões bem como as estratégias organizacionais são feitas com racionalidade e profissionalismo.

É notório que a grande maioria das empresas existentes no país hoje são organizações familiares, é o que mostra a pesquisa de Empresas Familiares no Brasil (2016), cerca de 80\% das 19 milhões existentes. De acordo com Leite (2002), as empresas familiares compõem um tipo específico de organização, pois os membros da família passam a interagir em graus e funções administrativas voltadas para o mundo dos negócios.

No Brasil, um estudo divulgado pela Fundação Dom Cabral - FDC em 2015 mostra que 60\% dos empregos formais existentes são ofertados por empresas familiares. $\mathrm{O}$ mesmo estudo ainda relata que $62 \%$ do PIB nacional provêm dessas organizações. O Brasil é destaque e referência nesse cenário empresarial.

409 Id on Line Rev. Mult. Psic. V.12, N. 42, Supl. 1, p. 408-426, 2018 - ISSN 1981-1179 Edição eletrônica em http://idonline.emnuvens.com.br/id 
Por outro lado, existe um grande emprazamento que essas empresas precisam enfrentar e superar, se quiserem se consolidar no mercado competitivo, é o de manter uma boa qualidade de gestão e, sobretudo a gestão de pessoas, uma vez que os recursos humanos são a parte mais delicada de uma empresa.

Por esse motivo levanta-se o seguinte questionamento: qual a percepção dos trabalhadores formais em relação a gestão de pessoas nas empresas familiares da cidade? A fim de atingir o objetivo maior supracitado, foi definido o seguinte objetivo específico: identificar a compreensão dos trabalhadores formais sobre o que é empresa familiar, uma vez que essa informação servirá de base crucial para condução e conclusão desta pesquisa.

O presente trabalho justifica sua relevância acadêmica em face de seu teor investigado, uma vez que tal assunto necessite ser mais aprofundado bem como esclarecido, trazendo benefícios para os gestores de organizações familiares, fornecendo-lhes informações vitais para seu negócio, como também, a luz dos trabalhadores formais, trará um esclarecimento maior acerca do assunto investigado.

Dessa forma, justifica-se também sob o aspecto social e pessoal, uma vez que o autor deste projeto adquire experiência no assunto, bem como a descoberta de novas informações e técnicas administrativas serão dispostas na pesquisa a fim de servir como base teórica para futuras pesquisas e aprofundamentos no tema.

\section{Referencial Teórico}

\section{Empresas Familiares}

De acordo com Bornholdt (2005), uma empresa familiar pode ser entendida como a união de pessoas dentro de uma organização em função de suas atribuições societárias e valores familiares. Embora o conceito ainda não seja um senso comum entre os teóricos, sobre o que pode ser definido como conceito de empresa familiar, várias teorias surgem com pesquisas afim de esclarecer e definir o conceito da temática. Como mostra Sharma, Chrisman e Chua (1997), pois em suas pesquisas, foram apresentadas pouco mais de trinta teorias diferentes.

Toda essa diversidade de conceitos se dá pela forma em que cada teórico lida e aborda a temática, pois muitos autores se fundamentam em fatores como propriedade, controle e direção. Para Fortes et al. (2013) empresa familiar é marcada por ser controlada por sócios, pertencentes a uma ou mais famílias, dessa forma, o modo de gerenciamento societário pertence aos sócios fundadores e aos seus descendentes.

410 Id on Line Rev. Mult. Psic. V.12, N. 42, Supl. 1, p. 408-426, 2018 - ISSN 1981-1179 Edição eletrônica em http://idonline.emnuvens.com.br/id 
De acordo com Cavedon \& Ferraz, (2003) e Bertucci et al., (2009) o conceito de empresa família e a própria motivação para a criação de um empreendimento desse tipo, possuem pontos em comum, como por exemplo, a relação entre a família e empresa e o âmbito de propriedade. Do mesmo modo, o conceito de família diante da sociedade moderna se ampliou. Surgiu então a necessidade de um entendimento mais apurado das modalidades de família.

Segundo Poutziouris (2001), uma empresa familiar pode possuir dois lados, positivo e negativo, ou seja, vantagens e desvantagens. A vantagem, ou o lado positivo, é o despertar do lado empreendedor das pessoas de uma família, a lealdade e o comprometimento com a estratégia organizacional bem como também o respeito e o orgulho às tradições familiares. Em contrapartida, as empresas familiares podem sofrer com a falta de profissionalismo, com o nepotismo, a dificuldade de enfrentar desafios, os conflitos familiares em relação ao planejamento, à liderança, à gestão e à sucessão, o que dificulta o desenvolvimento organizacional.

\section{Gestão de Pessoas}

De acordo com Araújo (2006), a gestão de pessoas antes era conhecida como Administração de Pessoal em 1930, e suas principais funções eram apenas recrutar e selecionar, e seus métodos eram bastante simples, pois bastassem apenas as pessoas, ao procurarem emprego, seriam imediatamente contratadas, caso houvesse vagas disponíveis na empresa.

O desenvolvimento desse modelo de gestão mostra uma função que se originou e evoluiu conforme às condições históricas, passando por intensas transformações correlatas ao mundo do trabalho. Os fatores contextuais são determinantes para a sua dinâmica (MAXIMIANO,2004).

Conforme Wright (2001), a gestão de pessoas tem auferido um lugar de maior destaque nas grandes e pequenas organizações do mercado global, apesar de algumas corporações ainda não tenham um setor específico dedicado a esse modelo de gestão, essa ainda sim, ela é trabalhada de maneira indireta, porém com muito critério, visando atingir os objetivos e definir estratégias.

Conforme Maier e Cruz (2014, p.02):

Assim, pode-se dizer que a Gestão de Recursos Humanos consiste no planejamento da organização, no trabalho com pessoas, em ter sensibilidade no ato de gerenciar as ideias dos colaboradores com benefícios do trabalho da empresa. É uma área multidisciplinar que envolve vários conhecimentos em diversas áreas (MAIER e CRUZ, 2014, p.02). 
Segundo Maximiano (2010), o planejamento estratégico é uma das ferramentas mais importantes na administração bem como no processo decisório de uma organização. Ele completa afirmando que o planejamento é uma dimensão de competências de modo a influenciar o futuro, o que corrobora com Montana et al (2010), que afirma que o processo decisório está diretamente ligado as estratégias para determinar o destino da empresa.

Esse instrumento surgiu afim de preparar as empresas para os futuros imprevistos e desafios enfrentados no ambiente mercadológico. Segundo Hart e Banbury (1994), apud Belmonte e Freitas (2013), é um dos meios mais eficientes que as empresas dispõem para lidar com as frequentes mudanças no mercado competitivo.

O planejamento estratégico depende de outras seis ferramentas que auxiliam na tomada de decisão e condução dos negócios nas empresas. De acordo com a Endeavor Brasil (2017), são elas: missão, visão e valores; análise $360^{\circ}$; análise SWOT; as 5 forças de Porter; matriz BCG e a definição de metas.

\section{Gestão de Empresas Familiares}

Nas empresas familiares, aspectos e fatores culturais influenciam diretamente na tomada de decisões estratégicas dos dirigentes. De acordo com Fleury e Fischer, (1989) e Moraes (2004 apud MAIA, 2009):

Gestores de empresas familiares, com maior ou menor ênfase de membros da família como em quaisquer tipos de empresas devem conduzir ações e atividades para o atendimento de necessidades e objetivos organizacionais, práticas de gestão que envolve o planejamento (decisão), organização, direção (liderança) e controle.

Isso mostra que os gestores devem estar atentos a muitos detalhes que são de suma importância para o sucesso da organização, tais como: planejamento estratégico, processo sucessório, cultura organizacional, controle, clima organizacional e gestão de recursos humanos.

Dos exemplos citados acima, o processo sucessório é talvez um dos pontos cruciais na perpetuação da organização. De acordo com Dutra (2010), a estruturação de um processo sucessório "implica em um posicionamento claro da organização sobre qual a contribuição esperada das pessoas e as vantagens de conhecer mais a fundo a respeito delas". O autor afirma ainda que esse processo é uma fora de avaliar quais são as pessoas mais adequadas para assumirem maiores responsabilidades, demonstrar a capacidade da empresa desenvolver e capacitar pessoas para assumirem posições mais críticas dentro da organização bem como identificar as fragilidades da empresa.

412 Id on Line Rev. Mult. Psic. V.12, N. 42, Supl. 1, p. 408-426, 2018 - ISSN 1981-1179 Edição eletrônica em http://idonline.emnuvens.com.br/id 
Conforme Lacombe e Tonelli, (2001) e Wright et al., (2001), a gestão de pessoas nas empresas remete aos quatro pilares da área de recursos humanos, que são eles: recrutamento, seleção, avaliação de desempenho, desenvolvimento e remuneração. O mesmo ainda afirma que em uma probabilidade de valorização das pessoas, o foco da administração de recursos humanos também abrange a busca das melhores práticas para os funcionários.

\section{Cultura Organizacional das Empresas Familiares}

De acordo com Schein (1984), a cultura organizacional pode ser entendida como um conjunto de princípios básicos aprendido por um grupo dentro de uma organização em meio a resoluções de problemas externos e adaptação interna. De todos os elementos que definem a cultura organizacional, os valores são os que mais se destacam, pois de acordo com Freitas (1991), são considerados o cerne que sustenta e orienta a organização.

Segundo Maia (2009), o conceito de empresa familiar possui pontos em comum com a família, empresa o campo de propriedade e a até mesmo a motivação para a criação de um negócio familiar e completa sua afirmação dizendo que isso se estende de modo que os valores e tradições influenciam no modelo de gestão de um negócio familiar.

Conforme Haugh e Mckee (2004), os valores incluem modos de comportamento, cooperação, economia, cortesia, autonomia, humor, obediência e integridade moral. Essas características corroboram com o pensamento de Fleury e Fleury (1995), que afirma que os elementos visíveis tais como, o comportamento aparente dos colaboradores, formas de comunicação e processos de gestão expressam valores básicos que norteiam o ciclo de vida da organização.

\section{Metodologia}

Inicialmente o estudo está fundamentado em levantamento bibliográfico de caráter descritivo com abordagem quati-qualitativa que de acordo Cooper e Schindler (2001) e Gil (2009), preenche aos seguintes objetivos: descrever fenômenos ou características que se associam à população-alvo; estimar as proporções de uma população que possuam determinada característica; descobrimento de associações entre a diversidade de variáveis.

Segundo Gil (2009), as pesquisas descritivas, assim como as exploratórias, são as que os pesquisadores sociais costumam realizar quando se preocupam com a atuação prática. O método de

413 Id on Line Rev. Mult. Psic. V.12, N. 42, Supl. 1, p. 408-426, 2018 - ISSN 1981-1179 Edição eletrônica em http://idonline.emnuvens.com.br/id 
estudo descritivo avalia as características de uma população específica, através de amostras, limitandose a ela.

Em relação ao tipo de pesquisa, a mesma caracteriza-se como pesquisa de opinião que consiste na coleta de informações coma a finalidade de mensurar as atitudes e a captação das opiniões das pessoas sobre os mais diversos temas

As pesquisas de opinião são assim caracterizadas quando a descrição de valores subjetivos que passam a ser mais fundamentais do que mesmo apresentar os melhores resultados estatísticos, conforme Pirolo e Fochi (2001).

Para o levantamento dos dados investigados, foram abordadas pessoas que estão vinculados a organizações formais de trabalho, as quais seguiram o modelo proposto conforme descrito no referencial teórico deste trabalho. Foram abordados 100 trabalhadores formais de diversas localizações do Brasil, no entanto obteve-se uma maior discrepância para as cidades da Região do Cariri, a coleta de dados foi realizada no mês de outubro do ano corrente.

Os meios utilizados para obtenção das informações que se utilizou para investigação seguiram os princípios metodológicos propostos. $\mathrm{O}$ instrumento mais adequado para a pesquisa em questão é a utilização de um breve questionário com perguntas objetivas e/ou subjetivas que de acordo com Marconi e Lakatos (2008), procuram sempre esclarecer o objetivo da natureza e da importância da pesquisa.

Entretanto, o pesquisador poderá possuir um script, para cada pergunta, baseado na teoria que tornará evidente o que se pretende como resposta, podendo o mesmo ser descartado caso o pesquisado não os mencione ou não necessite.

\title{
Análise e Discussão dos Resultados
}

Na presente seção, serão apresentadas as informações coletadas na pesquisa de campo realizada entre os dias 23 a 25 de outubro.

\section{Gráfico 1: Gênero}

\section{Gênero}

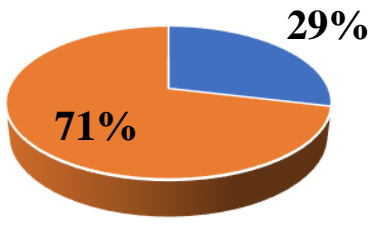

\author{
- MASCULINO \\ FEMININO
}

Fonte: Dados da pesquisa (2018) 
Através da pesquisa pode-se perceber um cenário diferente do habitual, onde se evidencia um quadro em que a maioria dos trabalhadores formais é do sexo feminino, sugerindo a compreensão da hipótese de que as mulheres estão mais capacitadas para o mercado de trabalho formal, enquanto que os homens estão seguindo o caminho do trabalho informal.

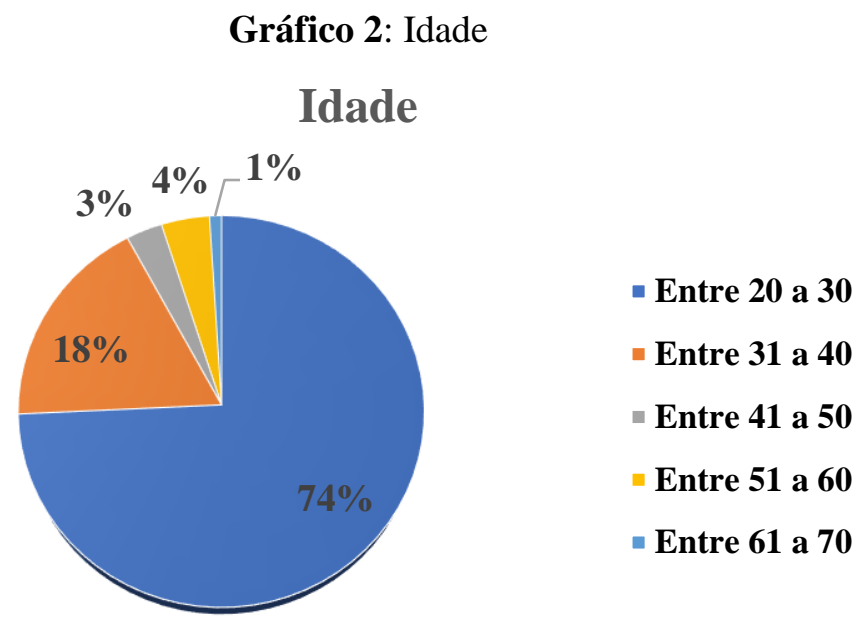

Fonte: Dados da pesquisa (2018)

Neste gráfico é possível perceber que o mercado de trabalho formal em sua grande maioria é composto por pessoas jovens com média de idade entre 20 a 35 anos. Esse perfil é talvez o ideal para o mercado de trabalho, pois é nessa fase da vida em que as pessoas buscam cada vez mais conhecimentos técnicos a fim de aperfeiçoarem os já adquiridos bem como se capacitarem cada vez mais frente ao mercado de trabalho que cada vez mais fica exigente em seus critérios de escolha de profissionais.

Gráfico 3: Estado civil

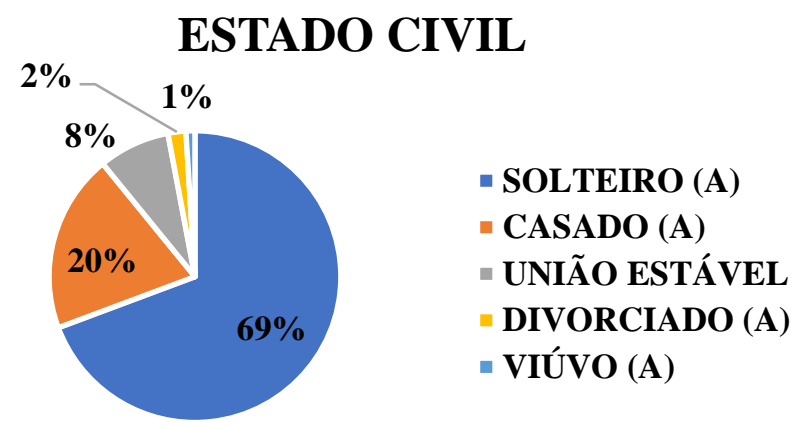

Fonte: Dados da pesquisa (2018) 
De acordo com a pesquisa, o perfil do trabalhador formal mostra outro fator importante, o estado civil. Isso reflete que a maioria das pessoas que atuam hoje no mercado de trabalho são pessoas buscam em primeiro plano a estabilidade profissional. Com um perfil jovem e disposto a buscar seu espaço no mercado, estes por sua vez optam por alcançar suas metas profissionais antes de firmarem um relacionamento estável, como um matrimonio, por exemplo.

Gráfico 4: Possui filhos

\section{POSSUI FILHOS}

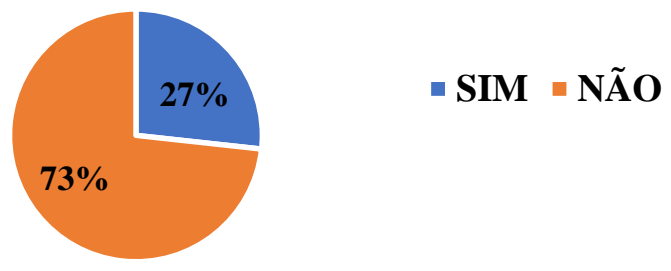

Fonte: Dados da pesquisa (2018)

Em conformidade características com os gráficos 2 e 3, o perfil do profissional também mostra que a grande maioria ainda não possui filhos, levando a crer nas hipóteses de que os jovens profissionais presentes no atual mercado de trabalho estão buscando cada vez mais a sua independência tanto profissional quanto social. Uma vez em que há a relação entre o perfil de um profissional jovem, solteiro e sem filhos, essas premissas são suficientes para comprovar essas hipóteses.

Gráfico 5: Qual cidade reside

\section{Em qual cidade reside?}

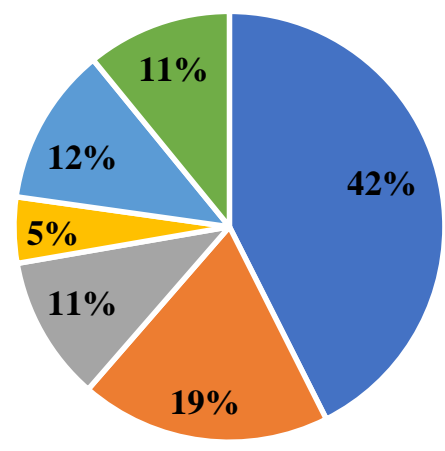

- Juazeiro do Norte-CE

- Crato-CE

- Mauriti-CE

- Barbalha-CE

- Outras cidades do Ceará

- Outras cidades do Brasil

Fonte: Dados da pesquisa (2018) 
Através da pesquisa realizada pode-se perceber que a maioria dos participantes reside na cidade de Juazeiro do Norte-CE enquanto outros residem em cidades próximas, situadas na região do Cariri, como por exemplo, Crato, Mauriti e Barbalha. Isso mostra bem o perfil e a percepção dos trabalhadores da região caririense acerca do que se pretendeu investigar. Mas isso não é exclusivo dessa determinada região, o gráfico ainda revela que $23 \%$ dos entrevistados residem em outras localidades, até mesmo fora do Ceará, conforme explícito acima.

Gráfico 6: Em qual cidade trabalha

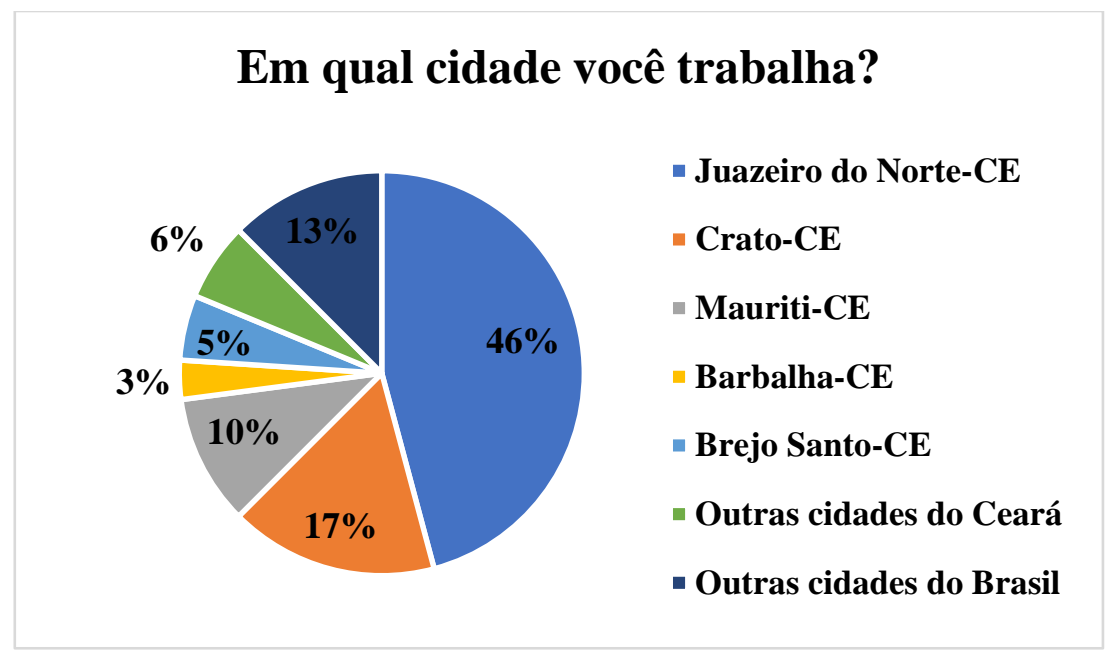

Fonte: Dados da pesquisa (2018)

O gráfico acima é bastante semelhante ao gráfico anterior, com um percentual de $46 \%$ dos participantes residentes na cidade de Juazeiro do Norte-CE. Isso mostra que essa cidade possui altos índices de trabalhadores formais em comparação às cidades vizinhas, como por exemplo, Crato e Barbalha.

Gráfico 7: Já trabalhou em uma empresa familiar

\section{Você já trabalhou em alguma empresa familiar?}

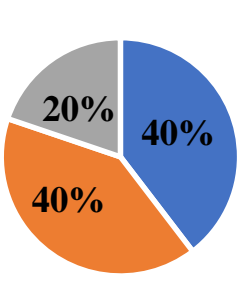

- JÁ TRABALHEI

Fonte: Dados da pesquisa (2018) 
No gráfico 7 é possível perceber uma pequena diferença na relação entre os trabalhadores que atuam ou já atuaram em empresas familiares e os trabalhadores que nunca trabalharam ainda em uma empresa do segmento. Esse dado é peculiar considerando que conforme a pesquisa das Empresas Familiares no Brasil (2016) existe cerca de 19 milhões de empresas no país e 80\% dessas, são organizações familiares.

O que torna o fato ímpar, uma vez que se levado em conta que $40 \%$ dos participantes da pesquisa afirmaram que nunca trabalharam em uma organização familiar, é também considerar que todos os participantes são trabalhadores formais e que em algum momento de suas carreiras, poderia ter feito parte de uma organização familiar.

Gráfico 8: Conhece alguém que trabalha em uma empresa familiar

\section{Você conhece alguém que trabalha em uma empresa familiar?}

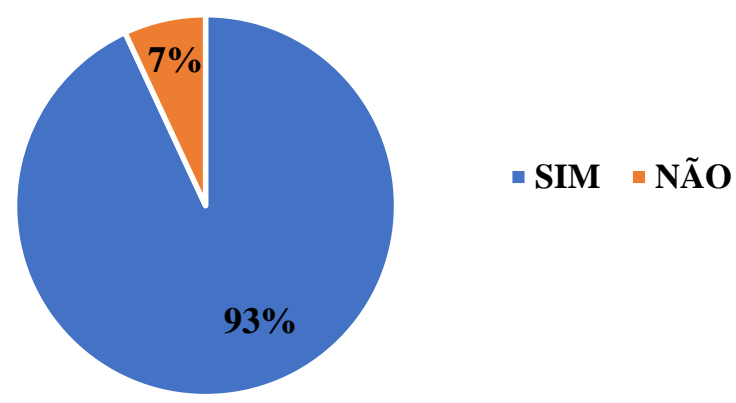

Fonte: Dados da pesquisa (2018)

Muito embora no gráfico anterior tenha se constatado um percentual alto de pessoas que nunca trabalharam em uma organização familiar, no gráfico 8 é possível notar que quase uma totalidade dos participantes da pesquisa afirmam que conhecem pelo menos uma pessoa que trabalha em uma empresa do segmento. Desse modo, o resultado obtido com essa pergunta ratifica os dados levantados pela revista Exame (2015) onde ela afirma que a grande maioria das empresas de médio e pequeno porte, são organizações familiares. 
Gráfico 9: Qual a percepção em trabalhar em uma empresa familiar

Qual a sua percepção sobre trabalhar em empresas

familiares?

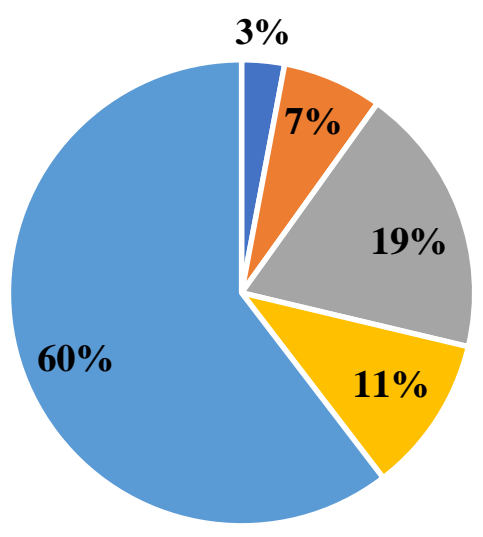

\author{
- Não trabalharia, existe \\ muito apadrinhamento \\ - Não trabalharia, pois vejo \\ poucas oportunidades de \\ crescimento neste modelo de \\ organização. \\ - Trabalharia/trabalho se não \\ tivesse outras opções
}

Fonte: Dados da pesquisa (2018)

De acordo com o gráfico 9, a percepção dos participantes da pesquisa quanto a possibilidade de trabalhar em uma empresa familiar é bem considerável. Com a afirmação positiva de $60 \%$ dos participantes, conclui-se que não há nenhum problema em trabalhar em uma organização familiar, muito embora ainda há afirmações de que somente trabalharia se, não houvesse outras opções disponíveis ou apenas por necessidades financeiras.

Gráfico 10: Conhece alguma empresa familiar em sua cidade

\title{
Em sua cidade você conhece alguma empresa familiar? Quantas?
}

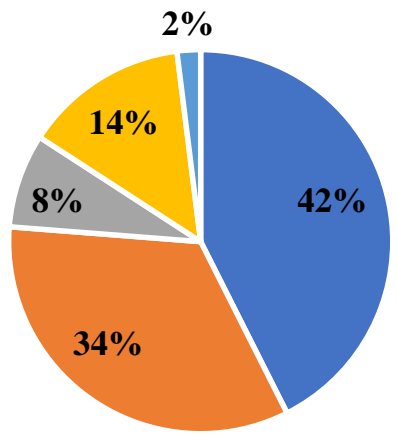

\author{
- Entre 1 - 3 \\ Entre $4-7$ \\ Entre 8 - 11 \\ - Mais de 12 \\ - Não conheço nenhuma \\ empresa
}

Fonte: Dados da pesquisa (2018) 
No gráfico acima, é possível constatar que $98 \%$ dos participantes da pesquisa conhecem pelo menos uma empresa do segmento familiar, onde $42 \%$ conhecem entre 1 e 3 empresas em sua cidade. As empresas familiares são consideravelmente representadas no território nacional, são cerca de $60 \%$ dos empregos formais pertencentes a organizações familiares, é o que afirma a pesquisa realizada pela Fundação Dom Cabral - FDC em 2015.

Gráfico 11: O que entende por gestão de pessoas

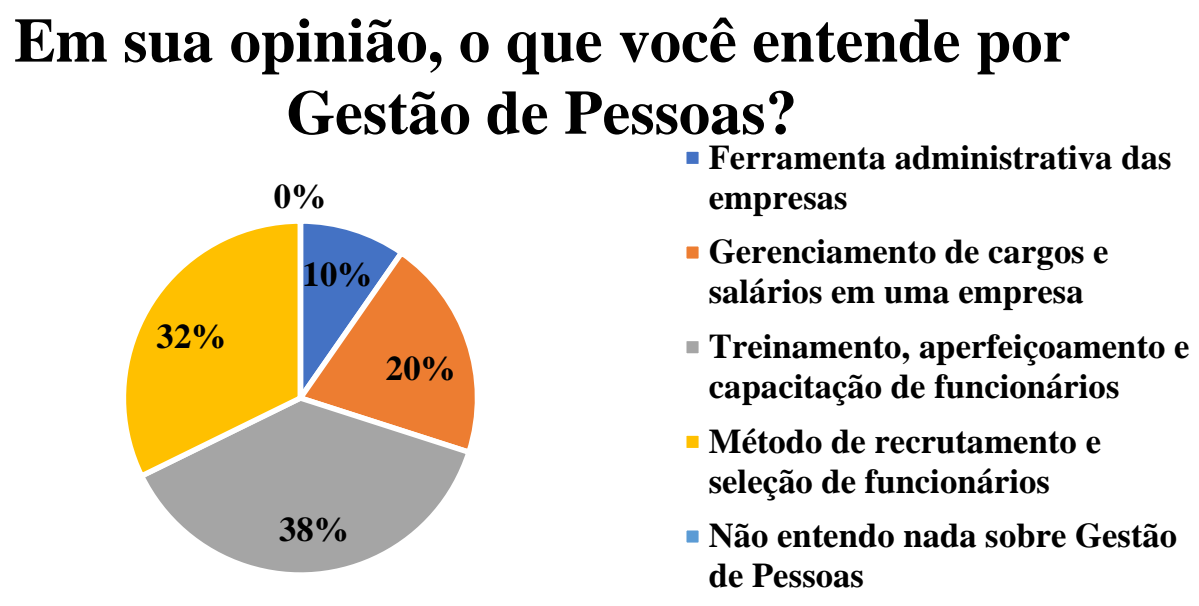

Fonte: Dados da pesquisa (2018)

Conforme demonstra o gráfico 11, nenhum dos participantes da pesquisa afirmou que desconhece a finalidade da gestão de pessoas, ou seja, de algum modo, todos os pesquisados entendem a gestão de pessoas de uma maneira específica. A maior parte delas entende que a gestão de pessoas é um modelo de treinamento e aperfeiçoamento dos funcionários em uma organização.

Em sentido geral, conforme o resultado da pesquisa, a gestão de pessoas é um conjunto que engloba técnicas administrativas empresariais, métodos de recrutamento e seleção de funcionários e gerenciamento de cargos que resumidamente se assemelha ao conceito de Maier e Cruz (2014, p.02) onde estes conceituam a gestão de pessoas como um planejamento estratégico da organização no trabalho com pessoas. 
Gráfico 12: A gestão de pessoas traz benefícios às organizações familiares

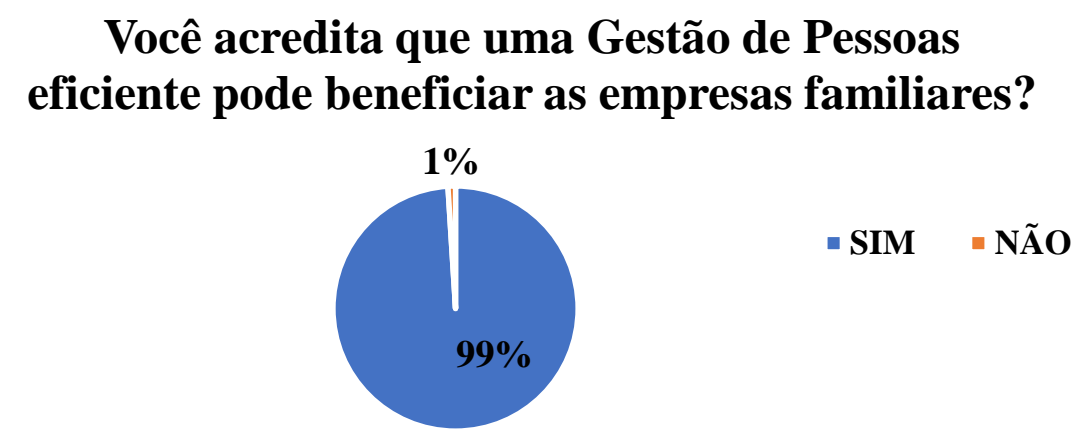

Fonte: Dados da pesquisa (2018)

De acordo com o demonstrativo do gráfico 12, a grande maioria, quase totalidade, dos participantes da pesquisa, acredita que a gestão de pessoas traz benefícios para uma organização familiar. Dessa forma é possível concluir que a gestão de pessoas nas organizações familiares pode ajudar estrategicamente nos processos decisórios, direcionando a gestão a um modelo mais profissional dessa gestão.

Nesse sentido, conforme Maia (2009) a ajuda da gestão de pessoas na profissionalização da organização familiar pode dar-se desde o processo de recrutamento e seleção e se estender por todas as áreas, fornecendo o devido suporte à empresa a fim de criar um modelo gerencial que gerem e agreguem capital intelectual.

Gráfico 13: Empresas familiares que possuam gestão de pessoas em sua gestão

\section{Você conhece alguma empresa familiar que trabalhe com a área de Gestão de Pessoas em sua administração?}

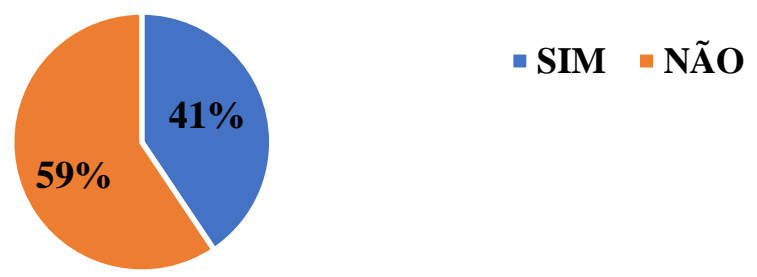

Fonte: Dados da pesquisa (2018) 
Conforme o gráfico 13 acima ainda existem muitas empresas familiares que não trabalham com a gestão de pessoas em sua administração, mas em contrapartida, há um certo equilíbrio entre as empresas que trabalham com a gestão de pessoas e empresas que não atuam com esse modelo.

De certo modo isso está ligado a aspectos da cultura organizacional, pois de acordo com Macedo (2001) o diretor fundador das organizações familiares representa a figura do proprietário e também do principal dirigente do negócio, e conforme o autor, essa pessoa tende a ter um comportamento patriarcal rígido, demonstrações de autoritarismo e outros traços divergentes de uma gestão eficientes como centralização do poder decisório, preferência por procedimentos informais entre outros diversos.

Gráfico 14: Vantagens da gestão de pessoas em empresas familiares

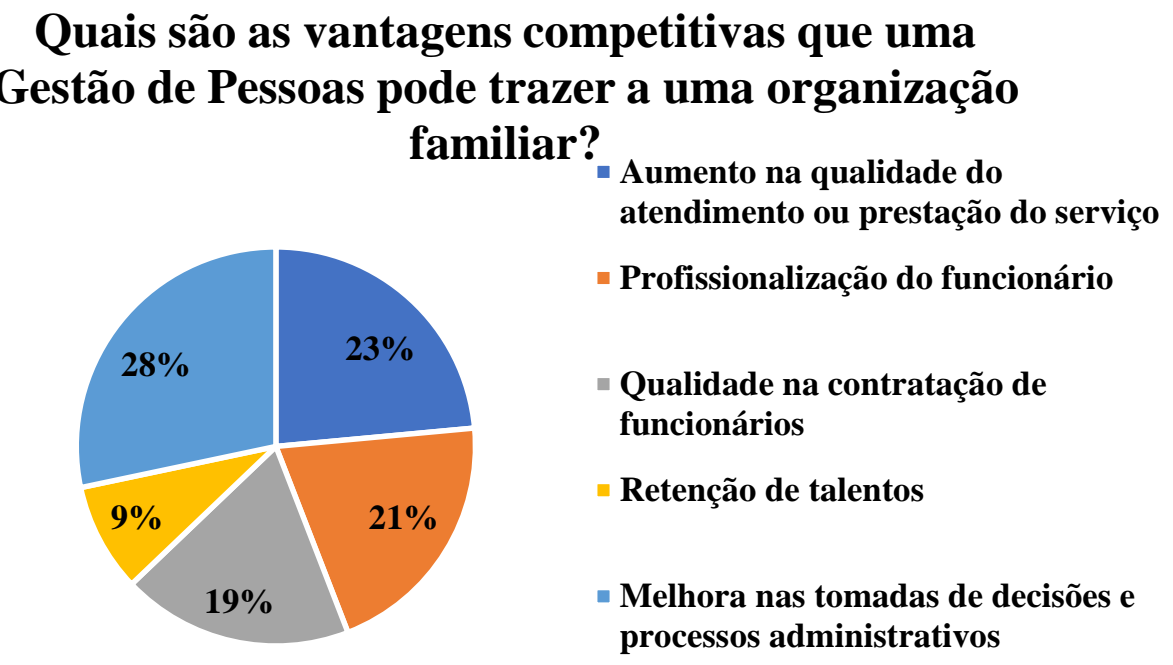

Fonte: Dados da pesquisa (2018)

No gráfico 14 pode-se perceber que há um grande equilíbrio entre quatro das principais vantagens que a gestão de pessoas profissional pode proporcionar a uma empresa familiar. Na opinião dos pesquisados os fatores mais benéficos não se destacam muito uns dos outros, levando a crer que um não é mais importante que o outro, mas sim, estão interligados como em um processo de melhoria contínua. Ainda que em menor percentual, a retenção de talentos também é considerado um beneficio da gestão de pessoas para empresas do segmento, pois conforme Vidigal (2000) e Rocha (2002) "o potencial intelectual dos funcionários não familiares precisa ser avaliado e aproveitado para não se perder talentos apenas pelo fato de não ser membro da família". 


\section{Considerações Finais}

O presente estudo teve como proposta inicial demonstrar a percepção dos trabalhadores formais acerca da profissionalização da gestão de pessoas em organizações familiares e seus principais benefícios para as mesmas.

Nesse sentido, a partir dos dados coletados pode-se concluir que os participantes da pesquisa em sua maioria são profissionais jovens e independentes que estão buscando sua colocação no mercado através de aperfeiçoamento constante por meio da educação profissional. Entretanto, esses profissionais não veem nenhum problema na possibilidade de trabalhar em uma organização familiar, que por sua vez, não os impediriam de empreender em seus próprios negócios.

A maior parte dos pesquisados são residentes da cidade de Juazeiro do Norte-CE, situada na região centro sul do Estado do Ceará e pertencente à região do Cariri. Essa região está atualmente em um constante desenvolvimento comercial e educacional, dispondo recursos suficientes para a geração de empregos, mão de obra qualificada e especializada e consequentemente para o surgimento de novas empresas, sobretudo familiares.

No entanto, a pesquisa revelou que apenas $40 \%$ dos entrevistados afirmaram que alguma vez em sua carreira, já trabalhou ou trabalha atualmente em uma empresa familiar, e apenas $41 \%$ afirma que conhece pelo menos uma organização do segmento que trabalhe com uma gestão de pessoas familiar.

Por outro lado, os pesquisados demonstram estar cientes das várias vantagens competitivas proporcionadas por esse modelo de gestão. Dentre as principais, $\quad$ o resultado da pesquisa demonstrou um empate técnico entre a melhoria na qualidade da prestação de serviços, qualidade na contratação de mão de obra, profissionalização dos colaboradores e melhora nas tomadas de decisões e planejamento estratégico.

Contudo, conclui-se que na percepção dos trabalhadores formais do atual mercado, a gestão de pessoas profissional é de fundamental importância para as organizações, sobretudo das familiares, principalmente quando se pretende obter vantagens competitivas sobre seus concorrentes bem como quando se tratar de planejamento estratégico a fim de melhorar e inovar as técnicas administrativas da organização.

\section{Referências}

ARAUJO, L. C. Gestão de Pessoas. São Paulo: Atlas, 2006. 
BELMONTE, V. A. B.; FREITAS, W. R. S. Empresas familiares e a profissionalização da gestão: estudo de casos em empresas paulistas. Rev. Adm. UFSM, Santa Maria, v. 6, n. 1, p. 71-90, JAN./MAR. 2013. Disponível em: <https://periodicos.ufsm.br/reaufsm/article/viewFile/2465/pdf> Acesso em: 15 mar 2018.

BERTUCCI, J. L. de O. Mecanismos de governança e processos de sucessão: um estudo sobre a influência dos elementos da governança corporativa na orientação do processo sucessório em uma empresa familiar. Revista Brasileira de Gestão de Negócios, São Paulo, v. 11, n.31, p. 152-167, abr/jun. 2009.

BORNHOLDT, W. Governança na Empresa Familiar: implementação e prática. Porto Alegre: Bookman, 2005.

CAVEDON, N.R. ; FERRAZ, O. L. Os diferentes modelos de família e empresa familiar e seus respectivos valores: um olhar sobre as empresas comerciais em Porto Alegre. Organização \& Sociedade, Salvador, v.10, n.27, maio/ago.2003.

COOPER, Donald R.; SCHINDLER, Pamela S. Métodos de Pesquisa em Administração. $7^{a}$ edição. Porto Alegre: Bookman, 2001.

CRESWELL, J. W. Projeto de Pesquisa: Método qualitativo, quantitativo e misto. Porto Alegre: Artmed, 2007.

DUTRA, J. S. Gestão de carreiras na empresa contemporânea. São Paulo: Atlas, 2010.

ENDEAVOR, 6 Ferramentas para fazer seu Planejamento Estratégico em 2017. Disponível em: <https://endeavor.org.br/ferramentas-planejamento-estrategico/> Acesso em: 22 mar. 2018.

FLEURY, A.; FLEURY, M. T. L. Aprendizagem e inovação organizacional: as experiências de Japão, Coréia e Brasil. São Paulo, Atlas, 1995.

FLEURY, M. T. L.; FISCHER. R. M. (Orgs) Cultura e poder nas organizações. São Paulo: Atlas, 1989.

FORTES, B. J. et. al. Gestão de empresas familiares: Estudo de caso em uma empresa de confecções. 2013, 16 f. Trabalho de Conclusão de Curso (Especialização) - Universidade Federal de Santa Maria, Santa Maria RS, 2013.

FREITAS, M. E. Cultura organizacional: formação, tipologias e impacto. São Paulo: Markron, 1991.

GIL, A. C. Como elaborar projetos de pesquisa. $4^{\text {a }}$ ed. São Paulo: Atlas, 2009.

HART, S.; BANBURY, C. How strategy-making processes can make a difference. Trategic Management Journal, v. 15, n. 4, p. 251-69, 1994.

HAUGH, H.; MCKEE, L. The cultural paradigm of the smaller firm. Journal of Small Business Management, v. 42. n. 4, p 377-394, 2004.

LACOMBE, B. M. B.; TONELLI, M. J. O discurso e a prática: o que nos dizem os especialistas e o que nos mostram as práticas das empresas sobre os modelos de gestão de recursos humanos. Revista de Administração Contemporânea, Rio de Janeiro, v. 5, n. 2, Maio/Ago. 2001. 
LEITE, R. C. As técnicas modernas de gestão de empresas familiares. In: GRZYBOVSKI, D.; TEDESCO, J. C. (Orgs). Empresa familiar: tendências e racionalidades em conflitos. $3 \mathrm{a}$ ed. Passo Fundo: UPF, 2002.

MACEDO, K. B. Empresa familiar brasileira: cultura, poder e decisão. Goiânia: Editora Terra Universidade Católica de Goiás, 2001.

MAIA, T. S. T. Gestão de Pessoas: Particularidades de Empresas Familiares. Revista Pensamento Contemporâneo em Administração, RPCA. Rio de Janeiro. v. 3. n. 2. mai./ago. 2009. 71-85. 71 ISSN 1982-2596. Disponível em: <http://www.uff.br/pae/pca/article/viewFile/88/72> Acesso em: 15 mar. 2018.

MAIER, R. I.: CRUZ, H. A. Gestão de Recursos Humanos: um Estudo na Empresa Grupo Adservi Ltda. de SC. XI Simpósio de Excelência em Gestão Tecnológica - SEGT 2014. Disponível em < https://www.aedb.br/seget/arquivos/artigos14/45120583.pdf> Acesso em: 02 mar. 2018.

MARCONI, M. A.; LAKATOS, E. M. Técnicas de Pesquisa. 7. ed. São Paulo: Atlas, 2008.

MARTINS, G. A. Manual para elaboração de monografias e dissertações. São Paulo: Atlas, 2002.

MAXIMIANO, A. C. A. Introdução à administração. 6. ed. São Paulo, Atlas,. 2004.

MAXIMIANO, A. C. A. Teoria Geral da Administração: Da Revolução Urbana à Revolução Digital. 6.ed. São Paulo, 2010.

MONTANA, P. J.; CHARNOV, B. H. Administração. 3.ed. São Paulo: Saraiva, 2010. 525 p. (Série Essencial). Paulo: Atlas, 2010. 491 p.

NETO, J. M. B. Como se faz pesquisa de opinião. Revista eletrônica PRPE. Fev. 2004. Disponível em <http://www.prpe.mpf.mp.br/internet/index.php/internet/content/download/1612/14366/file/RE_Joao MarquesBrandaoNeto.pdf> Acesso em: 26 set. 2018.

PIROLO, M. A. M.; FOCHI, M. A. B. A pesquisa de opinião: o "ver" e o "fazer" das relações publicas. INTERCOM - Sociedade Brasileira de Estudos Interdisciplinares da Comunicação XXIV Congresso Brasileiro da Comunicação - Campo Grande /MS - setembro 2001. Disponível em <http://www.intercom.org.br/papers/nacionais/2001/papers/NP5PIROLO.PDF> Acesso em: 26 set. 2018.

POUTZIOURIS, P. The strategic orientation of owner-managers of small ventures: vidence from the UK small business economy. International Journal of Entrepreneurial Behaviour and Research, v.9, n.5, p.185-214, 2003.

ROCHA, C. H. M. Profissionalização x modernização: um estudo de caso de uma empresa familiar do setor têxtil. In: ENCONTRO NACIONAL DA ANPAD, 26, 2002, Salvador. Anais... Salvador: ANPAD, 2002.

SCHEIN, E. Coming a new awareness of organizational culture. Sloan Management Review, Cambrigde, v.10, n.3, p 36-48, 1984.

SHARMA, P.; CHRISMAN J. J.; HUA, J. H. Strategic Management of the Family Business: Past Research and Future hallenges. Family Business Review, v. 10, n. 1, p. 1-35, 1997. 
SHARMA, P.; CHRISMAN, J. J.; CHUA, J. H. Strategic management of the family business: past research and future challenges. Family Business Review, v. 10, n.1, p.1-35, 1997.

SILVA, J. M.; SILVEIRA, S. Apresentação de trabalhos acadêmicos. Normas e técnicas. $2^{\mathrm{a}}$ edição. Petrópolis, J: Editora Vozes, 2007.

VIDIGAL, A. C. A sobrevivência da empresa familiar no Brasil. Revista de Administração da USP. São Paulo, v. 35, n. 2, p. 66-71, abr/jun, 2000.

WRIGHT, P. M.; McMAHAN, G. C.; SNELL, S. A.; GEHART, B. Comparing line and HR executives' perceptions of $\mathbf{H R}$ effectiveness: services, roles and contributions. Human Resource Management, vol. 40, n. 2, p. 111-123, Summer 2001.

\section{Como citar este artigo (Formato ABNT):}

TAVARES, Inguily Maiane de Sousa; RODRIGUES, Larissa Vasconcelos. A Percepção dos Trabalhadores Formais sobre a Gestão de Pessoas em Empresas Familiares. Id on Line Rev.Mult. Psic., 2018, vol.12, n.42, Supl. 1, p. 408-426. ISSN: 1981-1179.

Recebido: 07/11/2018;

Aceito: 08/11/2018 


\section{PESQUISA DE OPINIÃO \\ A PERCEPÇÃO DOS TRABALHADORES FORMAIS SOBRE A GESTÃO DE PESSOAS EM EMPRESAS FAMILIARES}

\section{PERFIL SOCIO-DEMOGRÁFICO}

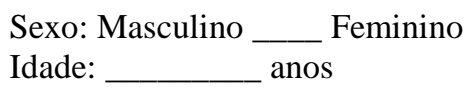

Estado Civil: Solteiro __ Casado (a)/União estável___ Divorciado(a)/Separado__ Viúvo (a) Número de Filhos:

Escolaridade: Analfabeto(a) ___ Alfabetizado __ Ensino Fundamental Ensino Médio Ensino Superior

EMPRESAS FAMILIARES: São aquelas em que uma Família detém o controle, em termos de nomear a gestão, e alguns dos seus membros participam e trabalham na empresa.

1. Você já trabalhou em alguma empresa familiar?
( ) TRABALHO EM UMA EMPRESA FAMILIAR ATUALMENTE
( ) JÁ TRABALHEI
( ) NÃO.

2. Você conhece alguém que trabalha em uma empresa familiar? ( ) $\operatorname{SIM}$ ( ) NÃO

3. Qual a sua percepção sobre trabalhar em empresas familiares?
a) Trabalharia/trabalho tranquilamente em uma organização familiar.
b) Trabalharia/trabalho só por necessidade financeira
c) Trabalharia/trabalho se não tivesse outras opções
d) Não trabalharia, existe muito apadrinhamento
e) Não trabalharia, pois vejo poucas oportunidades de crescimento neste modelo de organização.

4. Em sua cidade você conhece alguma empresa familiar? Quantas?
( ) Entre $1-3$
( ) Entre $4-7$
( ) Entre $8-11$
( ) Mais de 12
( ) Nenhuma/ não conheço

5. Em sua opinião, o que se entende por gestão de pessoas?
a) Método de recrutamento e seleção de funcionários
b) Ferramenta administrativa das empresas
c) Gerenciamento de cargos e salários em uma empresa
d) Treinamento, aperfeiçoamento e capacitação de funcionários
e) Todas as alternativas anteriores

6. Você acredita que uma gestão de pessoas profissional pode beneficiar as empresas familiares? ( ) SIM ( ) NÃO

7. Você conhece alguma empresa familiar que trabalhe com a gestão de pessoas em sua administração?
( ) SIM ( ) NÃO

8. Quais são as vantagens competitivas que uma gestão de pessoas pode trazer a uma organização familiar?
a) Melhora nas tomadas de decisões e processos administrativos
b) Aumento na qualidade do atendimento ou prestação do serviço
c) Profissionalização do funcionário
d) Qualidade na contratação de funcionários
e) Retenção de talentos 